\section{Colchicine-induced Somatic Polyploids from In Vitro-germinated Seeds of South African Watsonia Species}

\author{
Dave I. Thompson ${ }^{1}$ \\ NRF/SAEON Ndlovu Node, Scientific Services, Kruger National Park, \\ Private Bag X1021, Phalaborwa 1390, South Africa
}

Neil O. Anderson

Department of Horticultural Science, University of Minnesota, 286 Alderman

Hall, 1970 Folwell Avenue, St. Paul, MN 55108

\section{Johannes Van Staden ${ }^{2}$}

Research Centre for Plant Growth and Development, School of Biological and Conservation Sciences, University of KwaZulu-Natal Pietermaritzburg, Private Bag X01, Scottsville 3209, South Africa

Additional index words. bugle lily, flow cytometry, horticultural novelty, Iridaceae, marketability, mixoploid

\begin{abstract}
Polyploidy represents a useful tool for increasing marketability of floriculture crops. The efficacy of $250 \mu \mathrm{M}$ colchicine $[0.01 \%(\mathrm{w} / \mathrm{v})]$ as a means of inducing polyploidy in six South African Watsonia species (W. borbonica subsp. ardernei, W. humilis, $W$. laccata, W. lepida, W. pulchra, and $W$. vanderspuyiae), as determined through highresolution flow cytometry, is reported. Exposure to colchicine during imbibition and as 24-, 48-, or 72-h pulse treatments for in vitro-germinated seeds resulted in seedlings with increased ploidy, reaching a maximum of $60 \%$ induction after the 72 -h pulse treatment. The greatest proportions of induced individuals from both the pre- and post-germination exposure treatments were of mixed ploidy. These mixoploids were induced in five species. Non-chimeric tetra- and octaploids were produced in low frequencies only for $W$. vanderspuyiae during radicle-pulse exposure of 24 and $48 \mathrm{~h}$. Increasing colchicine exposure at radicle emergence manifested as aberrant phenotypic expression and was typified by a reduction in leaf length and rooting capacity in vitro coupled with overall slowed growth. In vitro regeneration and multiplication is easily achievable for the genus and should allow for the capture and refinement of desirable polyploid tissues.
\end{abstract}

Chromosome doubling has been used extensively as a tool for creating novelty in ornamental crops (Ascough et al., 2008; Hancock, 1997; Väinölä, 2000). Horticultural benefits of polyploidization include thicker stems and leaves, larger and more intensely colored flowers, novel flower coloration, lower phenotypic variability, a protracted flowering

Received for publication 28 Apr. 2010. Accepted for publication 30 June 2010.

We are grateful to the National Research Foundation (SA), the University of KwaZulu-Natal Research Fund (SA), the Richard E. Widmer Research and Education Fund (Minnesota), and the Minnesota Agricultural Experiment Station for financial assistance. We thank the School of Biochemistry, Genetics, Microbiology and Plant Pathology (University of KwaZulu-Natal, Pietermaritzburg) for allowing us access to their flow cytometer. We thank Dr. Paul Hills and the anonymous reviewers, whose comments greatly improved the manuscript. ${ }^{1}$ Previous address: Research Centre for Plant Growth and Development, School of Biological and Conservation Sciences, University of KwaZulu-Natal Pietermaritzburg, Private Bag X01, Scottsville 3209, South Africa.

${ }^{2}$ To whom reprint requests should be addressed; e-mail rcpgd@ukzn.ac.za.
(Chen et al., 2006), cotyledons (Stanys et al., 2006), and hypocotyls (Ascough et al., 2008; De Carvalho et al., 2005).

Conventional breeding and interspecific hybridization programs introduced new commercial cultivars of Babiana Ker Gawl. ex Sims, Freesia Klatt, Gladiolus L., and Ixia L. (Iridaceae), which are among the most soughtafter garden and container plants in the northern hemisphere (Fennell and Van Staden, 2003). Reports also confirm the use of spontaneous tetraploid genotypes in contemporary Gladiolus and Freesia lineages (Takatsu et al., 2001; Van Tuyl et al., 1992; Wulster and Ombrello, 2000). More recently, colchicineinduced polyploidy has been incorporated into the breeding of these genera as a means of increasing flower size, producing original color sports, and strengthening peduncles (Kim and De Hertogh, 1997). Ascough et al. (2008) used colchicine [50 to $250 \mu \mathrm{M} ; 0.002 \%$ to $0.01 \%(\mathrm{w} / \mathrm{v})$ ] to induce polyploids in pulsetreated hypocotyls of in vitro-germinated Watsonia lepida N.E.Br with a maximum success rate of $3 \%$.

The genus Watsonia Mill. (Iridaceae) comprises 52 southern African species with many horticulturally valuable characteristics but are often too tall (greater than $1 \mathrm{~m}$ ) for use outside of the cut-flower industry. Watsonias are perennial geophytes with cormous rootstocks and spicate inflorescences of brightly colored, long-lived flowers. Flowers are typically pink-purple or red-orange and individual inflorescences last several weeks. The basic chromosome number for the genus is $x=9$. All species are assumed diploid $(2 n=2 x=18)$, although sterile triploid genotypes $(2 n=3 x=$ 27 ) occur in $W$. meriana Mill. and $W$. aletroides Ker Gawl. (Goldblatt, 1989). There has been little commercial development in the genus with the exception of a few cultivars (viz. Watsonia borbonica 'Dazzler', 'Flamboyant', and 'Snow Queen') or species $[W$. borbonica (Pourr.) Goldblatt subsp. ardernei (Sander) Goldblatt, W. pillansii L.Bolus, $W$. pyramidata Stapf, $W$. rosea Ker Gawl.] and naturally occurring (Duncan, 2002) or induced (Thompson et al., 2005) dwarf phenotypes as container subjects. The aim of this study, as a means of addressing the delayed commercialization of the genus by releasing novel horticultural traits, was to establish the amenability of in vitro-germinated seeds to colchicine-induced polyploidy. The results of experiments dealing with the efficacy of $0.01 \%(\mathrm{w} / \mathrm{v})$ colchicine $(250 \mu \mathrm{M})$ as a means of inducing polyploidy in watsonia are reported.

\section{Materials and Methods} range $0.25 \mu \mathrm{M}[0.00001 \%(\mathrm{w} / \mathrm{v})$; Chen et al., $2006]$ to $38 \mathrm{~mm}[1.5 \%(\mathrm{w} / \mathrm{v})$; Stanys et al., 2006]. Actively growing tissues containing a meristem usually yield higher levels of polyploid induction and success has been found using germinating seeds (Pringle and Murray, 1992), ex vitro shoots (Contreras et al., 2007), roots (Kim et al., 2004), embryogenic and non-embryogenic callus (Gao et al., 2002; Suzuki et al., 2005), nodal segments
We used commercially sourced seeds (Silverhill Nurseries, Kenilworth, South Africa) of six Watsonia species chosen for their consistently high, rapid, and synchronous germination in preliminary in vitro trials. Phenotypically tall and natural dwarf species (W. humilis, $W$. laccata, and W. lepida; after Duncan, 2002) were included for comparison. Seeds were rinsed (1 min) in 100\% EtOH 
and subsequently decontaminated in $1.75 \%$ $(\mathrm{w} / \mathrm{v}) \mathrm{NaOCl}+1 \%(\mathrm{v} / \mathrm{v})$ Tween-20 for $20 \mathrm{~min}$. Seeds were then triple-rinsed in sterile $\mathrm{dH}_{2} \mathrm{O}$ before being placed on one-tenthstrength Murashige and Skoog media salts (Murashige and Skoog, 1962) supplemented with $0.01 \mathrm{~g} \cdot \mathrm{L}^{-1}$ myoinositol, $0.01 \mathrm{mg} \cdot \mathrm{L}^{-1}$ thiamine, $0.05 \mathrm{mg} \cdot \mathrm{L}^{-1}$ nicotinic acid, 0.05 $\mathrm{mg} \cdot \mathrm{L}^{-1}$ pyridoxine, and $0.2 \mathrm{mg} \cdot \mathrm{L}^{-1}$ glycine. The media $\mathrm{pH}$ was adjusted to 5.8 and solidified ( $8 \mathrm{~g} \cdot \mathrm{L}^{-1}$ UNILAB agar) in $60-\mathrm{mm}$ (internal diameter) glass culture jars. Depending on provenance, seeds were germinated either in the dark at $10 \pm 2{ }^{\circ} \mathrm{C}$ (for $W$. borbonica subsp. ardernei, $W$. humilis Mill., $W$. laccata Ker Gawl., and $W$. vanderspuyiae L. Bolus) or at $25 \pm 2{ }^{\circ} \mathrm{C}$ (for $W$. lepida and $W$. pulchra N.E.Br. ex Goldblatt) under Osram ${ }^{\circledR}$ 75-W cool-white fluorescent tubes (Osram South Africa, Midrand, South Africa) providing continuous illumination of $8.5 \mu \mathrm{mol} \cdot \mathrm{m}^{-2} \cdot \mathrm{s}^{-1}$ at culture level.

Colchicine exposure. In the first of two trials, seeds were subjected to the polyploidization treatment by incorporating $0.01 \%$ $(\mathrm{w} / \mathrm{v})$ colchicine into the germination medium, resulting in exposure to the mutagen during the period of imbibition and early embryo development. Seeds $(n=25$ per species) were removed from this enriched medium at radicle emergence (mean time taken to germination $=10 \mathrm{~d}$ ), triple-rinsed in sterile $\mathrm{dH}_{2} \mathrm{O}$, and transferred to a maturation medium without colchicine. In the second trial, seeds were immersed in a $0.01 \%(\mathrm{w} / \mathrm{v})$ colchicine-enriched bathing medium immediately after radicle emergence. This was achieved by aseptically transferring germinated seeds $(\mathrm{n}=25$ per treatment for each species) to $65-\mathrm{mm}$ (internal diameter) petri dishes containing colchicine-supplemented liquid ( $0 \mathrm{~g} \cdot \mathrm{L}^{-1}$ agar) germination media for pulse treatments of 24,48 , or $72 \mathrm{~h}$. Thereafter, seeds were triple-rinsed in sterile $\mathrm{dH}_{2} \mathrm{O}$ and transferred to a colchicine-free maturation medium. Formulation of the maturation medium in both trials was the same as the basic germination medium with maturation conditions of $25 \pm 2{ }^{\circ} \mathrm{C}$ under a continuous illumination at culture level of $8.5 \mu \mathrm{mol} \cdot \mathrm{m}^{-2} \cdot \mathrm{s}^{-1}$ supplied by cool-white Osram ${ }^{\circledR} 75$-W fluorescent tubes. Control seedlings were untreated and were assumed to be diploid.

Ploidy assessment. When seedlings had grown sufficiently to provide $0.3 \mathrm{~g}$ leaf tissue (6 to 12 weeks from transfer to the maturation medium), the nuclear DNA contents of treated and control plants were determined using high-resolution flow cytometry. Tissue samples from the distal tips of seedling leaves were macerated with a razor blade in $1 \mathrm{~mL}$ extraction buffer containing $100 \mathrm{mM} \mathrm{MgCl}$, $40 \mathrm{~mm}$ trisodium citrate, $22 \mathrm{~mm}$ 4-morpholinepropanesulfonic acid, and $0.1 \%(\mathrm{v} / \mathrm{v})$ Triton-X-100 with $\mathrm{pH}$ adjusted to 7.14. The suspension was filtered through a $50-\mu \mathrm{M}$ mesh filter and stained with $500 \mu \mathrm{L}$ propidium iodide, which binds specifically and stoichiometrically to DNA (Doležel, 1997). Fluorescence was measured using a Beckman Coulter Epics XL-MCL flow cytometer
(Beckman Coulter South Africa, Halfway House, South Africa) and the DNA content of colchicine-treated seedlings compared with data from control seedling tissue to establish ploidy. All fluorescent events (greater than $635 \mathrm{~nm}$ ) were displayed as histograms of the number of nuclei versus fluorescence intensity (relative DNA content; log amplification) within 1023 channels. Nuclei counts exceeded 5000 for each sample. Where possible, the ploidy of a minimum of 10 randomly chosen seedlings (independent trials) from within each treatment was established for each species. Before ploidy analysis, the gain of the cytometer was adjusted so that the $2 \mathrm{C}$ peak corresponding to $\mathrm{G}_{0} / \mathrm{G}_{1}$ nuclei isolated from leaf tips of diploid watsonia plants was localized on channel 200. This calibration was checked periodically throughout screening.

Before harvesting, seedling height (leaf length) was categorized as either normal or variously over- or undersized relative to controls, and seedlings were examined for other aberrant phenotypic character expression viz. localized organ necrosis, root definition and elongation, leaf definition, and overall growth rate. Seedling mortality was also recorded. After cytometric analysis, seedlings were assigned as being unaltered diploid, solid (non-chimeric), polyploid (tetra- or octaploid), or as various cytochimeric mixoploids with multiple histogram peaks.

\section{Results and Discussion}

Effect of colchicine on polyploidy induction. Flow cytometric histograms from control (diploid) watsonia seedlings exhibited nuclei populations at channels 200 and 400 (Fig. 1A), which correspond to $2 \mathrm{C}$ and $4 \mathrm{C}$ nuclei, respectively. In all control samples, the proportion of cells with DNA nuclear content equal to $2 \mathrm{C}$ exceeded $86 \%$ (minimum $86.1 \%$; maximum $98.9 \%$, data not shown). The correspondingly low frequencies of mitotic cells are typical of in vitro cultures; even young leaves produce desirable $\mathrm{G}_{0} / \mathrm{G}_{1}$ profiles dominated by single peaks because they are comprised predominantly of mesophyll (Galbraith et al., 1997).

Equivalent histograms from colchicinetreated seeds exhibited two or three populations of nuclei detected at any of channel numbers 200, 400, and 800 (Fig. 1B-D). These corresponded to $2 \mathrm{C}, 4 \mathrm{C}$, and $8 \mathrm{C}$ nuclei, respectively. Based on control data, we assumed a maximum of $14 \%$ of nuclei from both DNA diploid and DNA tetraploid plants were in $\mathrm{G}_{2}$. In instances in which the occurrence of $4 \mathrm{C}$ and $8 \mathrm{C}$ nuclei exceeded this "normal" $\mathrm{G}_{2}$ nuclei frequency, the presence of tetraploid and/or octaploid tissues was recorded.

The $0.01 \%(\mathrm{w} / \mathrm{v})$ colchicine provided to seeds, either before or at radicle emergence, was suitable for the induction of Watsonia polyploids (Table 1). However, exposure to colchicine at radicle emergence resulted in higher percentages of induction $(49 \%$ to $60 \%$ ) than was achieved after exposure during imbibition (Table 1). A maximum of $26 \%$ of seedlings derived from imbibition-treated seeds contained tissues with increased DNA content with the remaining seedlings (74\%) being unaltered from diploid $2 \mathrm{C}$ as indicated by the histogram peak in the same channel position (200) as the untreated control (Fig. 1A).

With the exception of the dwarf $W$. humilis, which appeared recalcitrant to changes in DNA content after this treatment, all species treated with colchicine pre-germination produced at least one polyploid seedling. Unfortunately, these polyploids were all cytochimeric (primarily $2 \mathrm{C}+4 \mathrm{C}$ and more rarely $2 \mathrm{C}+4 \mathrm{C}+8 \mathrm{C}$ mixoploids; Table 1 ). Octaploid 8C nuclei (at channel position 800) occurred only in $W$. vanderspuyiae and $W$. lepida, a phenotypically tall and a dwarf species, respectively.

By comparison, pooled and individual treatment data revealed that exposure to colchicine post-germination left fewer $(47.30 \%)$ unaltered diploid $2 \mathrm{C}$ seedlings than the previous treatment (Table 1). The remaining polyploid seedlings were predominantly cytochimeric mixoploids (primarily $2 \mathrm{C}+4 \mathrm{C}$, Fig. $1 \mathrm{~B}$; and $2 \mathrm{C}+4 \mathrm{C}+8 \mathrm{C}$, Fig. $1 \mathrm{C}$; and less frequently with $2 \mathrm{C}+8 \mathrm{C}$ or $4 \mathrm{C}+8 \mathrm{C}$ nuclei populations) and were produced in similar frequencies by all species. The occurrence of induced polyploids increased to a maximum of $60 \%$ when the treatment duration was extended to $72 \mathrm{~h}$. This is attributed to a marked increase in the occurrence of mixed $2 \mathrm{C}+4 \mathrm{C}+8 \mathrm{C}$ (Fig. 1C) nuclei populations, which approximately doubled for every $24-\mathrm{h}$ increase in colchicine exposure.

Application of colchicine at radicle emergence allowed for the low-frequency induction of solid tetraploid $4 \mathrm{C}$ and octaploid $8 \mathrm{C}$ seedlings (Table 1). The chromosome number of solid polyploids was assumed $2 n=4 x=$ 36 or $2 n=8 x=72$, respectively. Two tetraploid 4C individuals (Fig. 1D) were detected after 24-h exposure and a single octaploid $8 \mathrm{C}$ individual after $48 \mathrm{~h}$. These solid polyploids were induced only in the robust $W$. vanderspuyiae. The induction of solid polyploids in watsonia is important because mature polyploids could exhibit, over and above the much sought-after dwarf stature, at least one of the following economically beneficial characters: larger corms, increased flower size, and enhanced color intensity. These changes may be immediately apparent as the seedlings mature, but Hancock (1997) cautions that even among the most successful colchiploid agricultural and horticultural crops, considerable improvement has to be made on the raw polyploids before they can be released commercially. Additionally, it would need to be demonstrated that the increased levels of ploidy remain stable over time.

In this study, mostly mixoploids were induced with very few solid tetraploids or octaploids observed across treatments. These data are in line with Väinölä and Repo (2001), who produced mainly mixoploids and very few rhododendron tetraploids. In contrast, Suzuki et al. (2005) induced in excess of $40 \%$ solid Gladiolus tetraploids and none of 

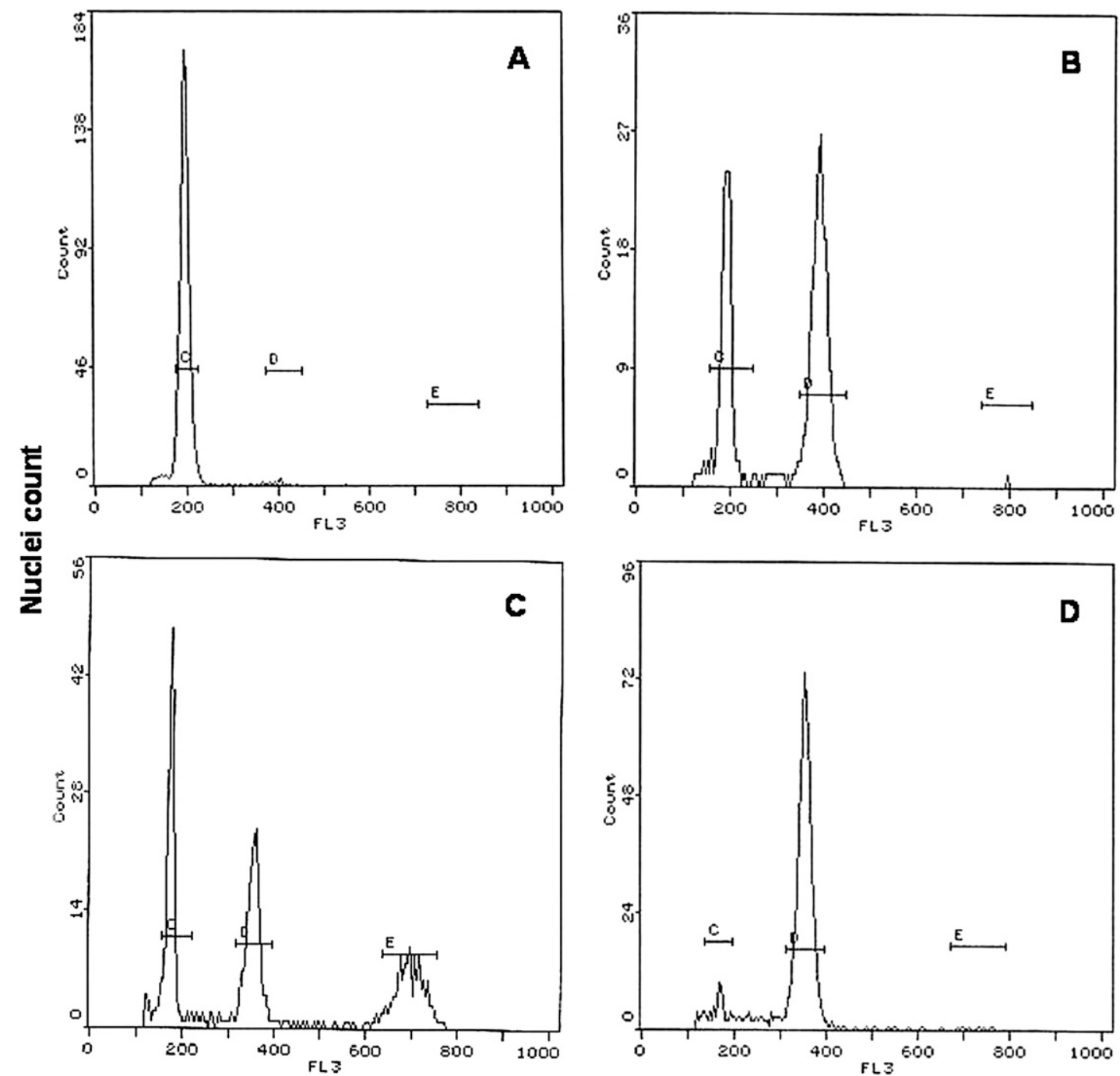

\section{Fluorescence (channel number)}

Fig. 1. Flow cytometric histograms of relative nuclear DNA contents of nuclei isolated from the leaves of watsonia seedlings. (A) A control, diploid Watsonia pulchra genotype. The 2C diploid peak was set at channel 200. Nuclei in the $\mathrm{G}_{2}$ phase of the cell cycle form a small peak (14\% or less of total nuclei detected) at channel 400. (B) A chimeric $W$. laccata individual with a large population of tetraploid nuclei (channel 400) in addition to a diploid peak. The seeds were exposed to colchicine during imbibition. (C) A W. lepida seedling showing mixed ploidy. Tetraploid and octaploid peaks occur at channels 400 and 800 , respectively. The eventual $\mathrm{G}_{2}$ peak for octaploid cells is out of scale. The seeds were pulse-treated with colchicine for $72 \mathrm{~h}$ at radicle emergence. (D) A solid tetraploid individual of $W$. vanderspuyiae with a dominant population of $\mathrm{G}_{0} / \mathrm{G}_{1}$ nuclei at channel 400 . $\mathrm{G}_{2}$ nuclei present at channel 800 . Seeds were pulsetreated with colchicine for $24 \mathrm{~h}$ at radicle emergence. The $\mathrm{x}$-axis is the relative fluorescence intensity (log amplification) within 1023 channels; the $\mathrm{y}$-axis is the number of nuclei encountered.

mixed ploidy. This discrepancy is likely the consequence of the choice of target tissue: rapidly dividing, single-celled callus cultures in the case of Suzuki et al. (2005) and entire seeds here. Successful polyploidization in watsonia seeds/seedlings therefore occurred, for the most part, in only some of the cells exposed to the antimitotic agent. One possibility of improving the induction efficacy of solid polyploids would be broadening the range of exposure (in terms of both colchicine concentration and treatment duration) or to use single cell or target explants (Ascough et al., 2008) in in vitro systems. Ascough et al. (2008) suggests the use of a liquid medium to further improve penetration of the a.i., a notion supported by the beneficial use of liquid-pulse treatments reported in this study.
Bearing in mind that mixaploid plants are a mosaic of variable-ploidy histogenic tissues, the current array of in vitro methodologies makes it feasible to isolate individual higher-level DNA protoplasts or cells or to excise complete tissues from chimeric individuals that have been produced using suboptimal methods. In this instance, the low number of polyploids produced and the likely requirement for further in vitro improvement need not be regarded as limiting as a result of amenability of Watsonia species to regeneration and multiplication in vitro (Ascough et al., 2007, 2008). However, mixaploid watsonia seedlings are interesting for reasons other than their ability to provide target tissue for further in vitro improvement and warrant continued study. For example, predominantly diploid azalea plants produce flowers wherein only the differently colored corolla margin is tetraploid, resulting in original color sports that represent an economically valuable source of variation (De Schepper et al., 2001, 2004).

Both solid and chimeric polyploid watsonia seedlings represent new possibilities for further breeding potential and horticultural production. These seedlings must therefore be monitored until it becomes possible to determine the effects of altered ploidy on growth rates, plant architecture, and flower morphology in reproductive adults and to ensure genome stability. In Watsonia, this process of monitoring and assessment is delayed because plants take several years to produce a sufficiently large corm to initiate 
Table 1. Ploidy induction (\%) in watsonia seedlings ${ }^{\mathrm{z}}$ after 1) imbibition and germination of seeds on colchicine-containing medium and 2) the pulsed exposure of seedlings to colchicine at radicle emergence.

\begin{tabular}{|c|c|c|c|c|c|c|}
\hline \multirow[b]{3}{*}{ Ploidy level ${ }^{\mathrm{y}}$} & \multicolumn{6}{|c|}{ Polyploid induction (\%) } \\
\hline & \multirow[b]{2}{*}{ Untreated } & \multirow[b]{2}{*}{ Pre-germination treatment ${ }^{\mathrm{x}}$} & \multicolumn{4}{|c|}{ Post-germination treatment ${ }^{\mathrm{w}}$} \\
\hline & & & $24 \mathrm{~h}$ & $48 \mathrm{~h}$ & $72 \mathrm{~h}$ & Pooled $^{v}$ \\
\hline $2 \mathrm{C}$ & 100 & 74 & 50.91 & 50.98 & 40.00 & 47.30 \\
\hline $4 \mathrm{C}$ & & & 3.64 & & & 1.21 \\
\hline $8 \mathrm{C}$ & & & & 1.96 & & 0.65 \\
\hline $2 \mathrm{C}+4 \mathrm{C}$ & & 21 & 32.73 & 29.41 & 22.22 & 28.13 \\
\hline $2 \mathrm{C}+4 \mathrm{C}+8 \mathrm{C}$ & & 5 & 7.27 & 15.69 & 33.33 & 18.76 \\
\hline $2 \mathrm{C}+8 \mathrm{C}$ & & & 1.81 & & 2.22 & 1.34 \\
\hline $4 C+8 C$ & & & 3.64 & 1.96 & 2.22 & 2.61 \\
\hline Polyploids (total) & 0 & 26 & 49.09 & 49.02 & 60 & 52.70 \\
\hline Mixoploids (total) & 0 & 26 & 45.45 & 47.06 & 60 & 50.84 \\
\hline Mortality $^{\mathrm{u}}$ & 0 & 0 & 0 & 7 & 23 & \\
\hline
\end{tabular}

${ }^{\mathrm{z}} W$. borbonica subsp. ardernei, W. humilis, W. laccata, W. lepida, W. pulchra, and W. vanderspuyiae. The data are independent of species.

${ }^{\mathrm{y}} \mathrm{n}=10$ seedlings per species per treatment. Ploidy was assessed 6 to 12 weeks after treatment.

${ }^{\mathrm{x}} \mathrm{n}=25$ seeds per species; colchicine included in the germination medium at $0.01 \%(\mathrm{w} / \mathrm{v})$ during an imbibition treatment.

${ }^{\mathrm{w}} \mathrm{n}=25$ seeds per species; colchicine included in the bathing medium at $0.01 \%(\mathrm{w} / \mathrm{v})$ for pulsed-immersion treatments of 24 , 48 , or $72 \mathrm{~h}$ applied at radicle emergence.

vPooled data represent the mean induction percentage following the pulsed exposure of seedlings to $0.01 \%$ (w/v) colchicine for 24 , 48 , and $72 \mathrm{~h}$ at radicle emergence.

uaximum percentage seedling mortality per treatment.

flowering. With the effects of genotype alteration on eventual phenotype being unknown at the time of treatment, breeders must therefore invest in plants that could ultimately exhibit a decline in marketable characteristics.

Effect on colchicine on in vitro seedling growth, morphology, and survival. Seed germination and subsequent seedling survival in watsonia were not influenced by pregermination colchicine exposure, with $100 \%$ of treated seeds maturing (data not shown). However, more treated seedlings displayed phenotypic aberrations (stunted and/or thickened leaves, reduced rooting) and comparatively slower growth rates than diploid $2 \mathrm{C}$ control seedlings, which were always without morphological abnormality (Fig. 2A). Typical symptoms of colchicine treatment are retarded growth and the production of distorted leaves (Cohen and Yao, 1996; Väinölä, 2000), both of which were observed in vitro during this study. Seedlings growing most vigorously and, therefore, that reached the required size for flow cytometric analysis first were confirmed as unaffected diploids or occasional $2 \mathrm{C}+4 \mathrm{C}$ mixaploids. On the basis of morphological abnormalities, nine stunted seedlings were assigned as putative polyploids. Cytometric evaluation confirmed these individuals as being mixoploid. However, seven morphologically "normal" seedlings were also revealed as being of mixed ploidy with exciting prospects for further development. Ultimately, 2C $+4 \mathrm{C}$ seedlings were either phenotypically normal $(54 \%)$ or stunted (46\%), whereas $2 \mathrm{C}+4 \mathrm{C}+8 \mathrm{C}$ seedlings were always stunted. These data are in keeping with Awoleye et al. (1994), who cautioned that the exclusive identification of polyploids based on altered morphology was not possible at the early stages of growth during which cytometric ploidy assessments were done. Furthermore, the distortion of growth may be transient and returns to normal when a balance is achieved in the mixture of variously doubled and undoubled tissues (Levin, 1983).

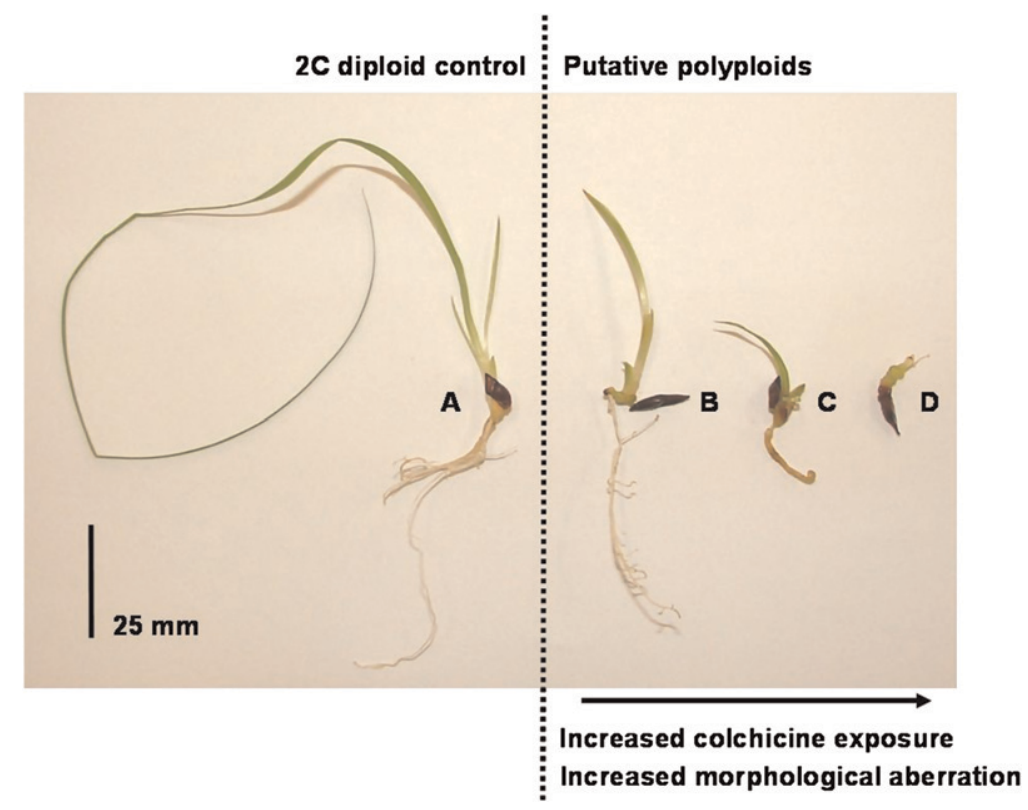

Fig. 2. The effect of increased pulse exposure to $0.01 \%(\mathrm{w} / \mathrm{v})$ colchicine at radicle emergence on seedling architecture in Watsonia vanderspuyiae. Seedlings were photographed 12 weeks after treatment. (A) A control 2C diploid individual showing leaf elongation and vigorous rooting in vitro. (B) A $2 \mathrm{C}+4 \mathrm{C}$ mixoploid displaying relatively normal phenotypic expression despite a slowed growth rate. The seed was pulse-treated for $24 \mathrm{~h}$. (C) A phenotypically aberrant 4C tetraploid individual with stunted leaves and reduced rooting. The other solid tetraploid produced was comparatively normal. Seeds were pulsetreated for $24 \mathrm{~h}$. (D) A highly aberrant individual unable to mature leaf or root tissues after a colchicine pulse treatment of $72 \mathrm{~h}$. The individual was later confirmed as a $2 \mathrm{C}+4 \mathrm{C}+8 \mathrm{C}$ mixoploid.

By comparison, exposure to colchicine at radicle emergence resulted in seedling mortality, reaching a maximum of $23 \%(W$. laccata; Table 1) after the 72-h treatment. Exposure to colchicine for $24 \mathrm{~h}$, which produced both $4 \mathrm{C}$ and $8 \mathrm{C}$ nuclei, was not associated with seedling death. Any horticultural benefit of higher polyploid yields from 48and $72-\mathrm{h}$ treatments would be nullified by these higher treatment-dependent mortality rates (Table 1). Increased ploidy levels therefore did not necessarily raise mortality rates, because healthy seedlings containing tetraploid and/or octaploid nuclei were produced in both the pre-germination treatment and after 24-h exposure at radicle emergence. It is not possible to definitively assign cause of death because only the nuclear DNA contents of living seedlings are known from this study. Rather, mortality may be more strongly influenced by the duration of exposure to $0.01 \%$ colchicine $(\mathrm{w} / \mathrm{v})$ needed to increase ploidy to the desired state rather than by the eventual level of ploidy achieved. This is in keeping with Väinölä and Repo (2001), who suggest that increased mortality in polyploids is not the consequence of an altered genotype. They argue that excessive colchicine exposure adversely 
affects non-meristematic tissues, resulting in aberrant morphologies, reduced vigor, and increased mortality. Protocols should therefore be designed to minimize colchicine exposure through choice of target tissue and by manipulating the exposure environment but while maintaining induction efficacy.

Colchicine exposure at radicle emergence resulted in a greater proportion of morphologically aberrant seedlings than did the pre-germination treatment with 57 stunted seedlings being classified as putative polyploids (Fig. 2B-D). Cytometric evaluation later confirmed these, and a further 22 morphologically "normal" individuals, as being polyploid. Like with the pre-germination treatment, $2 \mathrm{C}+4 \mathrm{C}$ mixoploid seedlings were either phenotypically normal (51\%) or stunted (49\%; Fig. 2B) relative to control seedlings (Fig. $2 \mathrm{~A}$ ), whereas $2 \mathrm{C}+4 \mathrm{C}+8 \mathrm{C}$, $2 \mathrm{C}+8 \mathrm{C}$, and $4 \mathrm{C}+8 \mathrm{C}$ seedlings were exclusively stunted and distorted (Fig. 2D). Levin (1983) reported that tetra- or octaploids typically grow more slowly than diploids throughout their lifespan, which could account for the higher frequency of growth retardation observed in plants with increased levels of ploidy. The single solid octaploid 8C seedling produced in this study was phenotypically stunted as was one of the two solid tetraploid 4C seedlings (Fig. 2C). In extreme cases, the distortion of leaf, shoot, and root morphologies was debilitating with seedlings being unable to mature roots or shoots (Fig. 2C-D). This state ultimately led to necrosis and seedling death under the seedling maturation conditions reported here; the challenge is to use these aberrant seedlings as a tissue source for further in vitro cultures and manipulation trials of the culture environment.

\section{Conclusions}

Both the pre- and post-germination applications of colchicine used here gave poor levels of solid polyploid production and a high frequency of chimera formation. However, the efficient in vitro multiplication observed for this genus will allow for the capture and manipulation of desirable solid polyploid tissues, even if produced in low frequencies. The authors therefore recommend manipulation of the timing and duration of colchicine application not only to increase transformation efficacy, but also to ensure seedling survival and relative morphological normality. These polyploid watsonias are expected to display traits horticulturally superior to their diploid forms, but adult phenotypic expression remains to be tested in this instance. Notwithstanding, the apparent amenability of the genus to colchicine-induced polyploidy during germination and their re- sultant polyploid status is exceptionally interesting for future breeding programs and the long-overdue commercialization of Watsonia as a genus.

\section{Literature Cited}

Allum, J.F., D.H. Bringloe, and A.V. Roberts. 2007. Chromosome doubling in Rosa rugosa Thunb. hybrid by exposure of in vitro nodes to oryzalin: The effects of node length, oryzalin concentration and exposure time. Plant Cell Rep. 26:1977-1984.

Ascough, G.D., J.E. Erwin, and J. Van Staden. 2007. In vitro propagation of four Watsonia species. Plant Cell Tissue Organ Cult. 88:135145.

Ascough, G.D., J.E. Erwin, and J. Van Staden. 2008. Effectiveness of colchicine and oryzalin in inducing polyploidy in Watsonia lepida N.E. Brown. HortScience 43:2248-2251.

Awoleye, F.M., M. Van Duren, J. Doležel, and F.J. Novak. 1994. Nuclear DNA content and in vitro induced somatic polyploidization in cassava (Manihot esculenta Crantz) breeding. Euphytica 76:195-202.

Caperta, A.D., M. Delgado, F. Ressurreição, A. Meister, R.N. Jones, W. Viegas, and A. Houben. 2006. Colchicine-induced polyploidization depends on tubulin polymerization in c-metaphase cells. Protoplasma 227: 147-153.

Chen, L.P., Y.J. Wang, and M. Zhao. 2006. In vitro induction and characterization of tetraploid Lychnis senno Siebold et Zucc. HortScience 41: 759-761.

Cohen, D. and J.L. Yao. 1996. In vitro chromosome doubling of nine Zantedeschia cultivars. Plant Cell Tissue Organ Cult. 47:43-49.

Contreras, R.N., T.G. Ranny, and S.P. Tallury. 2007. Reproductive behaviour of diploid and allotetraploid Rhododendron L. 'Fragrant Affinity'. HortScience 42:31-34.

De Carvalho, J.F.R.P., C.R. De Carvalho, and W.O. Otoni. 2005. In vitro induction of polyploidy in annatto (Bixa orellana). Plant Cell Tissue Organ Cult. 80:69-75.

De Schepper, S., L. Leus, T. Eeckhaut, E. Van Bockstaele, P. Debergh, and M. De Loose. 2004. Somatic polyploid petals: Regeneration offers new roads for breeding Belgian pot azaleas. Plant Cell Tissue Organ Cult. 76: 183-188.

De Schepper, S., L. Leus, M. Mertens, P. Debergh, E. Van Bockstaele, and M. De Loose. 2001. Somatic polyploidy and its consequences for flower colouration and flower morphology in azalea. Plant Cell Rep. 20:583590 .

Doležel, J. 1997. Application of flow cytometry for the study of plant genomes. J. Appl. Genet. 38: 285-302.

Doležel, J., M. Kubaláková, J. Bartoš, and J. Macas. 2004. Flow cytogenetics and plant genome mapping. Chromosome Res. 12:77-91.

Duncan, G. 2002. Dwarf Watsonias: Ten of the best for containers and rock gardens. Veld and Flora 88:94-98.
Fennell, C.W. and J. Van Staden. 2003. Biotechnology of southern African bulbs. S. Afr. J. Bot. 70:37-46.

Galbraith, D.W., G.M. Lambert, J. Macas, and J. Doležel. 1997. Analysis of nuclear DNA content and ploidy in higher plants, p. 7.61-7.6.22. In: Robinson, J.P. (ed.). Current protocols in cytometry. John Wiley and Sons, New York.

Gao, S.L., B.J. Chen, and D.N. Zhu. 2002. In vitro production and identification of autotetraploids in Scutellaria baicalensis. Plant Cell Tissue Organ Cult. 70:289-293.

Goldblatt, P. 1989. The genus Watsonia. National Botanical Gardens, Kirstenbosch, South Africa. p. 3-25.

Hancock, J.F. 1997. The colchicine story. HortScience 32:1011-1012.

Kim, K.-W. and A.A. De Hertogh. 1997. Tissue culture of ornamental flowering bulbs (geophytes). Hort. Rev. (Amer. Soc. Hort. Sci.) 18: 87-169.

Kim, Y.S., E.J. Hahn, H.N. Murthy, and K.Y. Paek. 2004. Effect of polyploid induction on biomass and ginsenoside accumulation in adventitious roots of ginseng. J. Plant Biol. 47:356-360.

Levin, D.A. 1983. Polyploidy and novelty in flowering plants. Amer. Nat. 122:1-25.

Murashige, T. and F. Skoog. 1962. A revised medium for rapid growth and bio assays with tobacco tissue cultures. Physiol. Plant. 15:473497.

Pringle, G.J. and B.G. Murray. 1992. Polyploidy and aneuploidy in the tamarillo, Cyphomandra betacea (Cav.) Sendt. (Solanaceae). II: Induction of tetraploidy, interploidy crosses and aneuploidy. Plant Breed. 108:139-148.

Sparnaaij, L.D. 1979. Polyploidy in flower breeding. HortScience 14:496-499.

Stanys, V., A. Weckman, G. Staniene, and P. Duchovskis. 2006. In vitro induction of polyploidy in Japanese quince (Chaenomeles japonica). Plant Cell Tissue Organ Cult. 84:263268.

Suzuki, K., Y. Takatsu, T. Gonai, and M. Kasumi. 2005. Plant regeneration and chromosome doubling of wild Gladiolus species. Acta Hort. 673:175-181.

Takatsu, Y., M. Kasumi, T. Manabe, M. Hayashi, E. Inoue, W. Marubashi, and M. Niwa. 2001 Temperature effects on interspecific hybridization between Gladiolus $\times$ grandiflora and $G$. tristis. HortScience 36:341-343.

Thompson, D.I., N.O. Anderson, and J. Van Staden. 2005. Watsonias as container plants: Using paclobutrazol for flowering and height control. S. Afr. J. Bot. 71:426-431.

Väinölä, A. 2000. Polyploidization and early screening of Rhododendron hybrids. Euphytica 112:239-244.

Väinölä, A. and T. Repo. 2001. Polyploidization of Rhododendron cultivars in vitro and how it affects cold hardiness. Acta Hort. 560:319-322.

Van Tuyl, J.M., B. Meijer, and M.P. Van Diën. 1992. The use of oryzalin as an alternative for colchicine in in vitro chromosome doubling of Lilium and Nerine. Acta Hort. 325:625-630.

Wulster, G.J. and T.M. Ombrello. 2000. Control of height and flowering of Ixia hybrids as container plants. HortScience 35:1087-1088. 